\title{
ANALISIS FAKTOR-FAKTOR YANG MEMPENGARUHI KEPUASAN KERJA (STUDI PADA TENAGA PENDIDIK DAN KEPENDIDIKAN PADA UNIVERSITAS DI BATAM
}

\author{
Jayana Salesti \\ Dosen Tetap Prodi Akuntansi Univeristas Riau Kepulauan Batam
}

\begin{abstract}
Penelitian ini bertujuan untuk mengetahui pengaruh dari variabel kebebasan bekerja, kejelasan peran, konflik kerja, rekan kerja , atasan , gaji promosi dan lingkungan kerja terhadap kepuasan kerja. Penelitian ini dilakukan dengan menyebarkan kuesioner pada 219 responden yaitu tenaga pendidik dan kependidikan pada universitas yang ada di Batam. Hasil penelitian ini diperoleh bahwa faktor kebebasan bekerja, kejelasan peran, konflik kerja, rekan kerja, atasan, gaji, promosi dan lingkungan kerja mampu menjelaskan 51,3\% variable kepuasan kerja, dan sisanya dipengaruhi variable lain. Secara parsial ditemukan hasilnya bahwa variable kebebasan bekerja, kejelasan peran dan kondisi lingkungan kerja mempunyai pengaruh signifikan positif terhadap kepuasan kerja, promosi mempunyai pengaruh signifikan negative, sedangkan variable rekan kerja, konflik kerja, dan hubungan dengan atasan tidak mempunyai pengaruh yang signifikan terhadap kepuasan kerja
\end{abstract}

\section{Pendahuluan}

Kepuasan kerja telah menjadi topik penting selama bertahun-tahun (Akfopure 2006). Hubungan antara manusia dan pekerjaan selalu menarik perhatian filosof karena sebagian besar hidup manusia dihabiskan di tempat kerja. Seorang karyawan yang puas dengan pekerjaannya akan melakukan tugasnya dengan baik dan berkomitmen untuk pekerjaan serta organisasinya. Oleh karena itu, sangat penting bagi pengusaha untuk mengetahui faktor-faktor yang dapat mempengaruhi tingkat kepuasan kerja karyawan mereka karena akan mempengaruhi kinerja organisasi juga.

Dalam sebuah artikel (Forbes 2013) dikatakan bahwa secara keseluruhan kepuasan kerja di Amerika menurun secara signifikan. Hal ini juga diungkapkan dalam sebuah artikel ( www.cnbc.com 2013), tentang hasil survey tahunan badan kepegawaian Kelly service, menyatakan bahwa hampir dari setengah populasi pekerja di dunia tidak puas dalam bekerja yaitu mencapai 48\%. Hal ini juga dikuatkan oleh sebuah arikel jobs sentral Malaysia, dikatakan bahwa orang dalam mencari pekerjaan orang akan memilih gaji yang tinggi atau gaji yang tidak terlalu tinggi tapi menjamin kepuasan kerja (Business News 2013). Padahal penelitian menunjukkan bahwa semakin puas para pekerja maka akan semakin efektif organisasi tersebut (Wolkwein \& Zhou ,2003).

Kepuasan kerja adalah seberapa besar karyawan senang atau tidak atas pekerjaan mereka Spector (1997). Dalam sebuah artikel yang diterbitkan oleh kompas 15 April 2013 dikatakan bekerja sebenarnya bukan sekadar aktivitas mencari penghasilan saja. Lebih dari itu, bagi perempuan, bekerja bisa menjadi sarana untuk mengaktualisasikan diri dan mendapat kepuasan pribadi.

Banyak hal yang diungkapkan dapat mempengaruhi kepuasan kerja. Menurut Heatfield (2000) kepuasan kerja dapat dipengaruhi oleh kesempatan untuk berkembang, meningkatkan skill komunikasi dan tujuan yang jelas rasa memiliki terhadap perusahaan dan feedback dari atasan. Menurut Survey yang dilakukan Accenture (2013 ) gender mempengaruhi juga terhadap 
kepuasan kerja, dilain pihak lembaga survey karir dari Amerika yang bekerjasama dengan FinanMost ITB mengungkapkan umur dan gender tidak terlalu berpengaruh terhadap kepuasan kerja, tetapi kebanyakan orang merasa tidak puas dengan pekerjaannya disebabkan karena kurangnya informasi tentang pekerjaannya dan tidak sesuai dengan latar belakangnya.

Menurut Yuang Ting (1997) kepuasan kerja dipengaruhi oleh faktor lingkungan kerja namun tidak terlalu dipengaruhi oleh karakter individu, sedangakan Ahmed (2010) menemukan bahwa kepuasan kerja dipengaruhi oleh faktor intrinsic dan extrinsic. Jassem (2010) mengungkapakn bahwa gaji adalah faktor yang paling signifikan mempengaruhi kepuasan kerja Marck (2012) baik faktor lingkungan kerja maupun karakter individu itu sendiri secara significant mempengaruhi kepuasan kerja. Danica (2013) menemukan bahwa kepuasan kerja dipengaruhi oleh faktor ekternal, subjektif dan faktor organisasinya . Disisi lain dalam sebuah artikel Forbes (2013 ) ada tujuh faktor yang mempengaruhi kepuasan kerja diantaranya nilai yang konsisten, tujuan jangka panjang, kepemimpinan, komunikasi, kolaborasi , kesempatan untuk berkembang dan kecepatan agility

Dosen , menurut PP 37 tahun 2009 adalah pendidik professional dan ilmuwan dengan tugas utama mentransformasikan, mengembangkan dan menyebarluaskan ilmu pengetahuan, tekhnologi dan seni melalui pendidikan, penelitian dan pengabdian masyarakat. Dengan demikian dosen termasuk tenaga pendidikan yang berperan penting menghasilkan generasi muda yang berkualitas sehingga perlu diperhatikan hal hal yang berkaitan dengan kepuasannya dalam bekerja agar menghasilkan sikap positif yang menunjang pekerjaannya.

\section{Landasan Teori}

\subsection{Konsep dan pengertian Kepuasan Kerja}

Kepuasan kerja (Job satisfaction) didefinisikan sebagai sesuatu yang menyenangkan atau emotional positif atas penghargaan dari sebuah pekerjaan atau pengalaman (locke,1976). Spector (1977) menyatakan kepuasan kerja adalah bagaimana orang menyenangi pekerjaan dan aspek yang berbeda dari pekerjaannya . Ellickson dan Logsdon (2002) mendukung pernyataan ini dengan mendefinisikan kepuasan kerja akan memperpanjang pekerja untuk menyukai pekerjaannya. Schermerhorn (1993 ) mendefinisikan kepuasan kerja sebagai sebuak afektif atau emosional respon terhadap berbagai aspek dalam pekerjaannya. Serupa dengan definisi yang dikemukakan oleh Price (2001) bahwa kepuasan kerja adalah afektif orientasi pekerja terhadap pekerjaannya . Secara singkat (Chen 2008 ) mendeskripsikan kepuasan kerja sebagai perasaan , sikap atau preferensi individu terhadap pekerjaannya

Hussaimi (2008) mengungkapkan kepuasan kerja atau ketidakpuasan kerja tidak hanya tergantung pada pekerjaan itu saja tapi juga tergantung dari dari harapan pekerja atas apa yang bias disediakan pekerjaan tersebut kepada pekerja. Menurut teori Abraham Maslow dan Frederick Herzberg, kepuasan kerja disebabkan oleh keinginan individu untuk memenuhi kebutuhan pribadi yang meliputi kebutuhan intrinsik dan ektrinsik .

Seseorang akan merasa puas apabila antara pekerjaan yang dilakukan dengan tujuan yang diharapkan terpenuhi . Semakin tinggi harapan seorang karyawan terpenuhi, maka akan semakin tinggi pula tingkat kepuasan yang dirasakan oleh karyawan atau pegawai tersebut dalam menjalankan pekerjaannya. Relly, Chatham dan Caldew (1991) dalam Jernigan dan Begs (2010) menyatakan bahwa kepuasan kerja kerja adalah sikap individu tentang persepsi mempertahankan pekerjaan mereka. Dengan kata lain dikatakan bahwa pegawai yang merasa puas akan terus bertahan dengan pekerjaannya dan memberikan persepsi positif dan menyenangkan terhadap pekerjaan yang dilakukannya. 
Kepuasan kerja didefinisikan sebagai perasaan atau sikap umum karyawan dalam kaitannya dengan pekerjaan mereka dan komponen kerja seperti lingkungan kerja, kondisi kerja, penghargaan yang adil, dan komunikasi dengan rekan-rekan (Glisson dan Durick, 1988; Kim 2005 ). Banyak model atau teori telah dilakukan mengenai kepuasan kerja. Menurut Robbins dan Judge (2009), kepuasan kerja menggambarkan perasaan positif tentang pekerjaan, hasil dari evaluasi karakteristiknya. Seseorang dengan tingkat tinggi kepuasan kerja memiliki perasaan positif tentang pekerjaan nya, sedangkan orang yang tidak puas memegang perasaan negatif. Kepuasan kerja adalah keadaan positif menyenangkan yang dihasilkan dari pekerjaan seseorang dan pengalaman kerja (Locke, 1976). Menurut Jain, Jabeen, Mishra \& Gupta (2007) individu menunjukkan sikap positif menyenangkan ketika mereka puas dengan pekerjaan mereka. Herzberg et al (1959) mendefinisikan paling dikenal populer "teori kepuasan kerja". Teori dua faktor mereka menunjukkan bahwa karyawan memiliki terutama dua jenis kebutuhan, terdaftar sebagai higienis dan motivasi. Faktor higienis adalah kebutuhan yang mungkin sangat puas dengan beberapa kondisi tertentu yang disebut faktor higienis (dissatisfiers) seperti pengawasan, hubungan interpersonal, kondisi kerja fisik, gaji, tunjangan, dan lain - lain .

\subsection{Hubungan antar Variabel}

\subsubsection{Hubungan Kejelasan peran (job clarity) dengan kepuasan kerja (job satisfaction)}

Yuang Ting (1997) menjabarkan bahwa kejelasan peran dalam bekerja itu adalah bagaimana dia mengetahui kewajibannya dan bagaimana aturannya agar dia bisa mencapai hasilnya dan bisa berkomunikasi dengan yang lain secara jelas . atau bisa juga dikatakan sebagai keinginan dari seseorang itu untuk mengetahui dengan jelas apa yang diharapkan dari mereka dan apa yang harus dia lakukan . Rizzo , House and Lirtzman (1970) mendefinisikan konsep kejelasan peran ini sebagai sesuatu dimana pekerja tahu apa yang diharapkan oleh mereka untuk memperoleh hasil dari tugas dan tanggung jawabnya .

Menurut Karim (2010) dengan membuat aturan yang jelas terhadap tugas dan tanggung jawab para karyawan akan dapat meningkatkan kepuasan terhadap pekerjaan mereka. Hal ini mendukung penelitian sebelumnya oleh (Gregersen and Black 1996; Palich, Home anda Griffeth 1995 )

Jack and schuler (as cited in spector 2000) juga mengungkapkan hubungan antara kejelasan peran dengan kepuasan kerja . Menurut Karim ( 2010 ) dan Gregersen and Black 1996; Palich, Home anda Griffeth 1995 kejelasan peran mempunyai hubungan yang signifikan positif dengan kepuasan kerja.

\subsubsection{Hubungan Konflik kerja (job conflict) dengan kepuasan Kerja (Job satisfaction)}

Konfik dalam pekerjaan didefinisikan oleh (Rizzo ;house dan Lirtsman 1970) bagian yang disetujui dengan permintaan yang ada antara pekerja dengan tempat bekerja . Seperti sebuah situasi dimana dua supervisor meminta untuk melakukan dua pekerjaan yang berbeda , atau pada saat pekerja harus melakukan dua tugas padahal dia hanya bisa untuk melakukan salah satunya ( Spector 2000)

Nauman (1993) dan Spectoor (2000) menemukan bahwa tedapat hubungan yang significant negative antara role conflict dengan kepuasan kerja. Hal ini juga diungkapkan oleh Yousef (2002) bahwa seseorang yang menerima tingkat konflik peran pada tingkat yang lebih tinggi sebagai sumber stress akan kurang puas dengan pekerjaannya.

Bedeian dan Armenakins (1981) yang menyatakan bahwa ada pengaruh negatif antara konflik peran, ambiguitas peran, dan kepuasan kerja. Fisher dan Gitelson (1983) yang mengungkapkan bahwa konflik peran berpengaruh negatif dengan kepuasan kerja 


\subsubsection{Hubungan antara rekan kerja (Co worker) terhadap kepuasan kerja (job Satisfaction)}

Kepuasan kerja individu dalam sebuah grup bisa saja dipengaruhi oleh hubungan dengan teman sekerjanya dan atasannya. Hubungan yang kooperatif dan suportif dari teman sekerja diharapkan dapat meningkatkan kepuasan dalam bekerja Dalam penelitian rizwan and khan (2012) ini temukan kerja tim menjadi faktor yang paling penting untuk kepuasan kerja karyawan , hal ini menjawab salah satu keterbatasan penelitian yuang ting (1997) . sedangakan Firth (2004 ) juga menemukan bahwa tingkat stress kerja dan support dari rekan kerja dan atasan mempengaruhi job satisfaction secara significant. Namun Ahmed (2010) dalam penelitiannya yang dilakukan pada staff non akademis di Universitas Punjab menemukan bahwa hubungan dengan teman sekerja tidak berpengaruh secara significant terhadap kepuasan kerja .

Hal serupa juga diungkapkn oleh lankau (1996) bahwa hubungan yang baik diantara teman kerja yang membentuk teamwork mempunyai pengaruh yang significant terhadap kepuasan kerja , sehingga dia menyimpulkan dengan memberikan support untuk meningkatkan kebersamaan dan hubungan yang baik diantara rekan kerja serta kerjasama yang baik dapat meningkatkan kepuasan kerja .

Hubber (2003) menjelaskan bahwa salah satu hal yang meningkatkan kepuasan kerja dari guru tingkat menengah dan menengah atas di texas adalah karena interaksi dan hubungan yang baik diantara mereka . Ketika seorang pekerja memberikan opsi kepada team dan rekan rekan sekerjanya dalam melakukan sesuatu dan mereka menerimanya untuk digunakan sebagai system yang dipakai dalam team mereka maka orang tersebut akan merasa puas, nylena et al (2005).

Scott et al (2003 ) rekan kerja dalam sebuah tim yang dapat memberikan support, dan melibatkannya dalam pengambilan keputusan, serta memberikan independensi kepada rekannya dalam mengerjakan tugasnya mempunyai pengaruh yang positif terhadap kepuasan kerja .

Penelitian (Mowday \&Suton 1993 ) menunjukkan bahwa kepuasan kerja berhubungan dengan peluang karyawan untuk berinteraksi dengan orang lain ditempat kerja. Penelitian telah menunjukkan bahwa terjadinya hubungan yang lebih baik diantara rekan kerja dapat meningkatkan kepuasan kerja (Wharton \& Baron 1991). Mnurut Staudt (1997) Hubungan sosial tersebut merupakan iklim yang penting dari "Iklim Sosial " ditempat kerja dimana hubungan yang baik sesama rekan kerja dapat menyebabkan efektivitas dalam suatu kelompok dan pekerjaan menjadi lebih menyenangkan, sebaliknya jika rekan kerja sulit untuk bekerja sama dengan baik maka akan berdampak negative terhadap kepuasan kerja . Hal ini senada dengan penelitian Luddy (2005) bahwa dampak rekan kerja yang bersahabat dapat mempengaruhi kepuasan kerja .

\subsubsection{Hubungan dengan atasan (Supervision) terhadap kepuasan kerja (Job Satisfaction )}

Hubungan dengan atasan lebih jelasnya terlihat dari komunikasi dengan atasan, menurut pincus (1986 ) komunikasi yang baik antara atasan dengan bawahan sangat menentukan kepuasan kerja dari karyawan. Menurut Jablim (1996) atasan atau supervisor adalah orang atau salah satu dari bagian organisasi yang mempunyai wewenang formal untuk megarahkan dan mengawasi bagian dari organisasi yang lainnya .

Penelitian menunjukkan bahwa hubungan antara atasan dan bawahan akan mempunyai pengaruh yang positif dan signifikan pada kepuasan kerja karyawan secara keseluruhan, Individu cendrung mempunyai kepuasan kerja yang tinggi jika supervisor atau atasannya memberikan dukungan dalam menyelesaikan tugas tugasnya, Ting (1997). Hasil yang sama juga disampaikan oleh Blilingsley dan Lintas (1992)serta cramer (1993) para peniliti ini berpendapat 
bahwa ketidakpuasan terhadap atasan atau pengawasan manajemen adalah penyebab signifikan dari ketidakpuasan kerja , temuan diatas dikuatkan oleh penelitian Staud's (1997) .

Chieffo (1997) menyatakan bahwa supervisor yang melibatkan karyawan atau bawahannya untuk berpartisipasi dalam membuat keputusan yang berhubungan dengan pekerjaan mereka dapat merangsang tingkat kepuasan kerja.

Menurut schuler (1997) jika hubungan anatara karyawan dengan atasan tidak baik maka karyawan cendrung tidak mengetahui peran mereka dalam menghadapi masalah dalam pekerjaannya . Dari penelitian yang dilakukan oleh (Jablin, 1979; Pincus, 1986; Schuler, 1979; Shih, 2000; Wheeless, Wheeless, \& Howard, 1983) karyawan yang atasannya memberikan arahan dan informasi yang jelas akan lebih puas dari pada karyawan yang atasannya tidak memberikan arahan dan informasi yang jelas. Hal serupa juga diungkapkn oleh lankau (1996) bahwa hubungan yang baik diantara teman kerja yang membentuk teamwork mempunyai pengaruh yang significant terhadap kepuasan kerja, sehingga dia menyimpulkan dengan memberikan support untuk meningkatkan kebersamaan dan hubungan yang baik diantara rekan kerja serta kerjasama yang baik dapat meningkatkan kepuasan kerja .

\subsubsection{Hubungan Gaji (salary) dengan kepuasan kerja (Job Satisfaction)}

Gaji atau kompensasi adalah sebuah angka dimana para pekerja menerima kompensasi atas pekerjaan yang dilakukannya pada periode tersebut ( Edward 1986 ). Edward (2009) dalam penelitiannya pada para tenaga pengajar di Malaysia, bahwa sebagian besar factor yang mempengaruhi kepuasan kerja baik di segala umur, lini dengan berbagai tingkat pendidikan adalah gaji . Hal ini sebelumnya sudah di ungkapkan hezberg f (1966) bahwa indicator dan motivator yang menunjang kepuasan kerja diantaranya adalah gaji

Lawyer (1991) menjelasakan bahwa kepuasan atas Gaji adalah perbedaan antara perseosi orang tersebut atas berapa yang harus mereka terima dan berapa yang nyatanya diterimanya .

Menurut Luthans (1998) gaji tidak hanya membantu orang untuk mencapai kebutuhan dasar mereka , tetapi juga berperan dalam memenuhi kebutuhan lainnya . Penelitian sebelumnya (Voydanoff 1980 ) telah menunjukkan bahwa kompensasi moneter adalah salah satu variable yang paling signifikan dalam menjelaskan kepuasan kerja . Dalam Studynya pada manager sector public Tylor dan Barat (1992) menemukan bahwa upah atau gaji mempengaruhi kepuasan kepuasan kerja .

\subsubsection{Hubungan Kesempatan untuk promosi dengan kepuasan kerja ( Job Satisfaction)}

Kemajuan seorang karyawan dari satu posisi ke posisi lain pekerjaan pekerjaan yang memiliki kisaran gaji yang lebih tinggi, sebuah jabatan yang lebih tinggi, dan, sering, tanggung jawab pekerjaan yang lebih dan lebih tinggi tingkat, disebut promosi. Kadang-kadang hasil promosi di seorang karyawan mengambil tanggung jawab untuk mengelola atau mengawasi pekerjaan karyawan lainnya (Susan M 2011). Robin (1998) menyatakan bahwa promosi memberikan kesempatan untuk pertumbuhan pribadi, peningkatan tanggung jawab dan meningkatkan status sosial

Menurut Gaether \& Nollen (1992) karyawan biasanya ingin bekerja pada perusahaan yang menyediakan mereka kesempatan untuk lebih maju atau dalam kata lain mempunyai peluang dalam kariernya. Peneliatian ini mengungkapkan bahwa karyawan yang mempunyai kesempatan berkarier lebih baik akan merasa lebih puas dari pada karyawan yang bekerja pada perusahaan yang tidak memberikan peluang untuk maju. Hal ini juga didukung oleh penelitian Heathfield (, 2000) yang mengungkapkan bahwa salah satu dari lima hal yang paling diinginkan karyawan dalam pekerjaannya adalah menginginkan kesempatan untuk dapat mempunyai jalur 
karir dan kesempatan ke pekerjaan yang lebih baik. Dengan kata lain diungkapkan bahwa karyawan akan lebih merasa puas jika dia punya kesempatan untuk bisa mempunyai pekerbangan yang lebih maju dalam pekerjaannya. Hal yang senada juga diungkapkan oleh Bigliardi, Petroni, dan Dormio (2005) yang melakukan penelitiannya pada para insinyur desain , bahwa perusahaan bisa meningkatkan kepuasan para insinyur tersebut dengan menyediakan peluang karir yang lebih baik .

Kesempatan karyawam untuk promosi juga cenderung memberikan pengaruh terhadap kepuasan kerja (Landy 1989; Lawood 1984; Moorhead \& Griffen 1992; Kinicki\& Vecchio1994 ). Bull (2005) Kebanyakan orang mengalami kepuasan ketika mereka percaya bahwa prospek masa depan mereka baik. Sebaliknya Jika orang merasa bahwa mereka memiliki kesempatan terbatas untuk kemajuan karir maka kepuasan kerja mereka akan menurun.

Menurut Ma Comicck dan LLgen (1985), kepuasan karyawan dengan kesempatan promosi akan tergantung pada sejumlah factor, termasuk kemungkinan akan dipromosikan serta dasar dan keadilan dari promosi tersebut. Selain itu tidak semua karyawan ingin dipromosikan, alasannya karena itu berkjaitan dengan fakta bahwa promosi itu melibatkan tanggung jawab yang lebih besar dan tugas tugas yang lebih kompleks dimana individu menganggap diri mereka belum siap. Meskipun demikian kesempatan untuk promosi tampaknya memiliki korelasi positif yang signifikan dengan kepuasan kerja (Staud ,1997)

\subsubsection{Hubungan Kondisi Kerja (Work Condition) dengan Kepuasan kerja (job Satisfaction)}

Kondisi kerja meliputi faktor eksternal seperti tempat bekerja lingkungan suhu danlain lain, faktor subjective hingga faktor faktor yang berhubungan dengan shift kerja , jam kerja , hingga peralatan yang menunjang pekerjaannya Bubble (2006 ). Kondisi kerja adalah factor lain yang memiliki dampak kepada kepuasan kerja karyawan Luthan et al (1992). Menurut Luthans (1998), jika orang bekerja ditempat yang bersih ramah lingkungan mereka akan merasa lebih senang untuk pergi bekerja, sebalik nya jika kondisi kerja tidak nyaman maka orang akan merasa sulit untuk menyelesaikan tugas tugasnya

Kondisi dimana tempat kerja dalam kondisi normal akan menunjang pekerja melakukan pekerjaannya dengan baik, sehingga puas dengan pekerjaannya, sementara dengan kondisi yang tidak memadfai dapat menurunkan motivasi mereka dalam menyelesaikan pekerjaannya sehingga kepuasan kerja juga negatif Wadhwa (2011)

Voster (1992) menyatakan bahwa kondisi kerja hanya akan cenderung memiliki dampak yang signifikan terhadap kepuasan kerja ketika terjadi suatu kondisi kerja yang baik sangat baik atau sangat buruk. Selain itu keluhan karyawan mengenai kondisi kerja yang sering berhubungan dengan manifestasi dari masalah yang mendasari . Luthans et al (1992)

Adapun beberapa hipotesis yang diturunkan untuk mencapai tujuan dari penelitian antara lain sebagai berikut:

Berdasarkan teoritis yang telah diuraikan di atas, maka dirumuskan hipotesis yang menjadi acuan dalam penelitian adalah:

H.1 Diduga kebebasan bekerja mempunyai pengaruh terhadap kepuasan kerja

H.2 Diduga kejelasan Peran dalam bekerja berpengaruh terhadap kepuasan kerja

H.3 Diduga konflik dalam pekerjaan berpengaruh terhadap kepuasan kerja

H.4 Diduga hubungan dengan rekan sekerja berpengaruh terhadap kepuasan kerja

H.5 Diduga hubungan dengan atasan berpengaruh terhadap kepuasan kerja

H.6 Diduga gaji berpengaruh terhadap kepuasan kerja

H.7 Diduga Kesempatan untuk promosi berpengaruh terhadap kepuasan kerja 
H.8 Diduga Kondisi lingkungan kerja berpengaruh terhadap kepuasan kerja H.9 Diduga kebebsan bekerja, kejelasa peran, konflik dalam bekerja, hubungan dengan rekan kerja, hubungan dengan atasan, gaji , kesempatan promosi dan kondisi lingkungan kerja secara simultan berpengaruh terhadap kepuasan kerja

\section{$3 \quad$ Metodelogi Penelitian}

Target populasi penelitian adalah Tenaga pendidik dan kependidikan Universitas yang ada di Batam, diantaranya Universitas Riau Kepualaun, Universitas Internasional Batam, Universitas Batam dan Universitas Putera Batam. Metode pengambilan sampel dengan menggunakan teknik purposive sampling yaitu dengan kriteria responden adalah Dosen dan staff yang bekerja secara full Time pada Universitas yang ada di Batam. Unit analisis dari penelitian ini adalah unit analisis tingkat individu.

Horison waktu yang digunakan dalam penelitian ini adalah studi satu tahap (one shot study). Pengumpulan data dilakukan dalam satu tahap yaitu pada bulan Januari sampai dengan April 2014 dan data yang dikumpulkan dapat berupa data dari satu atau beberapa subjek penelitian yang mencakup satu atau beberapa periode (Indriantoro \& Supomo 1999).

Teknik Pengumpulan Data

Data yang akan digunakan dalam penelitian ini adalah data primer yang dikumpulkan dengan menggunakan metode survei melalui penyebaran kuesioner secara langsung kepada responden. Data yang diperlukan untuk penelitian ini antara lain: Umur, Jenis kelamin, tingkat pendidikan, lama bekerja, dan posisi atau jabatan responden. Hal ini diperlukan untuk mendukung analisis variable variable independen. Pengumpulan data dilakukan dengan membagikan kuesioner kepada Dosen dan staff universitas yang ada di Batam dan kuesioner dapat langsung dikumpulkan setelah selesai dijawab oleh responden melalui beberapa orang pengumpul data.

\subsection{Uji Kualitas data}

\subsubsection{Uji Outlier}

Pengujian ini dilakukan untuk mengetahui apakah terdapat jawaban responden yang menyimpang atas pertanyaan yang telah diajukan (Outlier) hal ini disikapi dengan menentukan adanya ambang batas atau yang didefinisikan sebagai outlier. Untuk menentukan uji ini dilakukan dengan Zscore. Nilai z-score lebih besar dari 3 atau lebih kecil dari -3 dianggap menyimpang. Maka data tersebut akan divalidasi dan tidak akan diproses untuk analisis selanjutnya. (Kurniawan 2011, Ghozali 2002).

\subsubsection{Uji Validitas ( Test of Validity)}

Uji validitas dilakukan untuk menguji akurasi pertanyaan-pertanyaan dalam kuesioner. Pengujiannya dilakukan dengan menggunakan pendekatan validitas konstruk (contruct validity) yang akan menguji apakah suatu instrumen mengukur konstruk sesuai dengan yang seharusnya diukur atau tidak. Uji validitas konstruk memakai pengujian statistik analisis faktor (factor analysis). Kuesioner dikatakan valid jika mempunyai factor loading $\geq 0,50$ (Kurniawan,2011,Ghozali, 2002). 


\subsubsection{Uji Reliabilitas (Test of Reliability)}

Uji reliabilitas digunakan untuk menguji konsistensi instrumen dalam mengukur suatu data dengan menggunakan cronbach's alpha. Suatu kuesioner dikatakan reliabel jika jawaban responden terhadap pertanyaan yang diajukan tetap konsisten atau tidak berubah meskipun pertanyaan atau kuesioner tersebut diajukan lebih dari satu kali. Suatu konstruk memiliki reliabilitas yang memadai apabila nilai Cronbach's Alpha lebih besar atau sama dengan 0.6 (Kurniawan, 2011, Ghozali, 2002).

\subsection{Metode Analisis Data}

\subsubsection{Metode Analisis Deskriptif}

Metode analisis deskriptif dalam penelitian pada prinsipnya merupakan proses transformasi data penelitian dalam bentuk tabulasi, sehingga mudah dipahami dan gampang diinterpretasikan. Statistik deskriptif adalah statistik yang memberikan gambaran atau deskripsi suatu data yang dilihat dari rata-rata, standar deviasi, varian, maksimum, minimum, kurtosis (Ghozali, 2002). Metode ini pada umumnya digunakan untuk mendeskripsikan gambaran tentang objek yang diteliti seperti karakteristik responden yang meliputi, jenis kelamin, usia responden, status pekerjaan, status pernikahan dan lama bekerja. Penyebaran data dikatakan valid jika nilai standar deviasi lebih kecil dari 30\% dari rata-rata (Kurniawan ,2011, Ghozali, 2002).

\subsection{Uji Asumsi Klasik}

\subsubsection{Uji Multikolinieritas}

Uji multikoliniearitas adalah untuk menguji apakah model regresi ditemukan adannya korelasi antar variabel bebas (independen). Model regresi yang baik seharusnya tidak terjadi korelasi antara variabel bebas. Multikolinearitas dapat diketahui dari variance inflative (VIF) dan nilai tolerance. Nilai umum yang dipakai adalah VIF $<10$ dan tolerance $>0.10$ yang berarti bebas dari multikoliniearitas (Ghozali,2002).

\subsubsection{Uji Normalitas}

Uji normalitas dilakukan untuk mengetahui apakah data yang diperoleh terdistribusi normal atau tidak. Metode statistik yang digunakan adalah dengan menggunakan metode analisis grafik normalitas dengan menggunakan pendekatan normal probability plot. Data dianggap normal jika data menyebar disekitar garis diagonal dan mengikuti arah garis diagonal, maka model regresi memenuhi asumsi normalitas (Ghozali, 2002).

\subsection{Uji Hipotesis}

Uji hipotesis bertujuan untuk mengetahui uji hipotesis yang merupakan jawaban sementara dari hasil perumusan permasalahan. Penelitian harus dapat membantu membuat keputusan apakah hipotesis ditolak atau gagal ditolak. Pengambilan keputusan harus melalui proses inferensi yang memerlukan penelitian dengan akurasi lebih (Indriantoro \& Supomo,1999).

Metode statistik yang digunakan dalam penelitian ini adalah analisis multiregresi atau regresi berganda. Analisis regresi adalah studi dasar untuk mengetahui pengaruh beberapa variabel independen terhadap variabel dependen (Ghozali,2002). Tujuan analisis regresi adalah untuk mengetahu dan memprediksi rata-rata populasi variabel dependen berdasarkan nilai dari variabel independen (Kurniawan, 2011, Ghozali, 2002).

\subsubsection{Uji statistik F}


Uji F dilakukan untuk melihat apakah model regresi dapat digunakan untuk memprediksi variabel dependen (Kurniawan, 2011). Tingkat probabilitas $<0,05$ dianggap signifikan atau model regresi tersebut dapat digunakan untuk memprediksi variabel dependen dan sebaliknya apabila tingkat probabilitas $>0,05$ dianggap tidak signifikan dan regresi tersebut tidak dapat digunakan dalam memprediksi variabel dependen (Kurniawan, 2011, Ghozali, 2002).

\subsubsection{Uji statistik $\mathrm{t}$}

Uji $t$ dilakukan untuk menguji signifikansi koefisien regresi dari setiap variabel independen. Tingkat signifikasi $<0,05$ berarti terdapat pengaruh antara masing-masing variabel independen terhadap dependen dan sebaliknya jika nilai signifikasi $>0,05$ maka tidak terdapat pengaruh antara masing-masing variabel independen terhadap dependen (Kurniawan, 2011, Gozhali, 2002).

3.4.3 Uji koefisien determinasi (Adjusted $\mathrm{R}^{2}$ )

Uji koefisien determinasi $\left(\mathrm{R}^{2}\right)$ digunakan untuk menjelaskan seberapa besar kemampuan model dalam menerangkan variabel dependen (Gozhali, 2002). Pengujian koefisien nilai $\mathrm{R}^{2}$ dapat dilihat dari berapa besar variabel independen dapat memberikan informasi terhadap variabel depeden. Apabila nilai $\mathrm{R}^{2}$ rendah maka dapat diartikan bahwa variabel independen memiliki kemampuan yang terbatas dalam menjelaskan variasi variabel dependen. Sedangkan apabila nilai $\mathrm{R}^{2}$ tinggi berarti variabel tersebut dapat memberikan hampir seluruh informasi yang diperlukan oleh variabel variabel terikat(Ghozali,2002).

\section{Hasil Penelitian}

Hasil penyebaran 255 kuesioner kepada para responden, terkumpul kembali sebanyak 225 kuisioner (88\%) dan sebanyak 219 responden (85\%) yang memenuhi syarat. Responden laki-laki sebanyak 75 responden (34.2\%) dan responden perempuan sebanyak 144 responden (65.8\%). Disini kita bisa melihat bahwa responden perempuan lebih banyak dibandingkan dengan responden laki-laki. sebagian besar responden berusia antara 25-48 tahun yaitu sebanyak 173 responden (79 \%) dan urutan kedua terbanyak adalah di usia dibawah 25 tahun yaitu 27 responden (12.3\%). Responden yang berusia 49-52 sebanyak 17 responden $(7.8 \%)$, dan sisanya usia 53-66 tahun sebanyak 2 responden atau ( $0.9 \%$ ). Latar belakang pendidikan responden pasca sarjana yaitu sebanyak 108 responden (49.3\%). Responden yang berlatar pendidikan sarjana (S1) sebanyak 77 responden atau (35,2\%), SMA sebanyak 20 responden atau $(9.1 \%)$ diploma sebanyak 11 responden ( $5 \%$ ) dan berlatar belakang pendidikan S3 sebanyak 3 responden $(1.4 \%)$. responden bekerja pada universitas tersebut, dimana persentase terbesar adalah pada responden yang sudah bekerja 2-3 tahun yaitu 61 responden $(27,9 \%)$, kemudian diatas 5 tahun sebanyak 59 responden $(26,9 \%), 1$ - 2 tahun sebanyak 43 responden $(19.6 \%)$, 34 tahun sebanyak 39 responden atau (17.8\% ) dan sisanya 4-5 tahun yaitu sebanyak 17 responden $(7.8 \%$ ). Berdasarkan jabatan sebanyak 115 responden $(50.2 \%)$ merupakan tenaga pendidikan, responden yang menjabat sebagai tenaga kependidikan sebanyak 58 (26.5\%) dan sisanya 46 responden $(21.0 \%)$.

\subsection{Hasil Uji Hipotesis}

Uji Hipotesis yang digunakan dalam penelitian ini adalah analisa regresi berganda, dimana terdapat 8 (Delapan ) Variabel independen diantaranya kebebasan bekerja kejelasan peran konflik kerja hubungan dengan rekan kerja, hubungan dengan atasan /supervisor gaji , 
kesempatan promosi dan kondisi lingkungan kerja dan satu Variable Dependen yaitu Kepuasan kerja (Job Satisfaction.)

\subsubsection{Hasil Uji F}

Hasil Uji F pada tabel 4.9 diperoleh nilai $\mathrm{F}$ hitung untuk analisis kebebasan bekerja (independent), kejelasan peran (Independent), Konflik kerja (independent), Hubungan dengan rekan kerja (independent), Hubungan dengan atasan / supervisor (independent), Gaji (independent), Promosi (independent), Kondisi lingkungan kerja (independent) dan kepuasan kerja (dependent)

Berdasarkan uji $\mathrm{F}$, diperoleh nilai $\mathrm{F}$ hitung sebesar 27.095 dengan tingkat lebih kecil dari signifikan 0.000. Nilai signifikan lebih kecil dari 0.05 sehingga model regresi kebebasan bekerja (independent), kejelasan peran (Independent), konflik kerja (independent), hubungan dengan rekan kerja (independent), hubungan dengan supervisor (independent), Gaji / pendapatan (independent), promosi (independent), kondisi lingkungan kerja (independent) secara simultan mempunyai pengaruh terhadap Job satisfaction sebagai variabel Dependent

\section{Tabel 4.9}

HasilUji F

\begin{tabular}{lcc}
\hline Model & F & Signifikan \\
\hline Regression & 27.095 & $0,000^{\text {a }}$ \\
\hline
\end{tabular}

Sumber: Data primer diolah (2014).

\subsubsection{Hasil Uji t}

Dari hasil uji t pada Tabel 4.10 menunjukan signifikansi variabel kebebasan bekerja adalah $0,000<0,05$ oleh karena itu Ho1 ditolak, , variabel kejelasan peran adalah $0,000<0,05$ oleh karena itu Ho3 ditolak, variabel konflik kerja adalah 0,667 > 0,05 oleh karena itu Ho4 diterima, variabel hubungan dengan rekan kerja adalah 0,140>0,05 oleh karena itu Ho5 diterima, varibel hubungan dengan atasan / supervisor adalah 0,740 > 0,05 oleh karena itu Ho6 diterima ,variablel gaji adalah 0,783 >0,05 oleh karena itu Ho7 diterima, variable promosi 0,031<0.05 berarti Ho ditolak dan variable Lingkungan kerja nilai signifikansinya $0.000<0,05$ berarti Ho9 ditolak

Dari hasil penelitian ini variable yang mempunyai pengaruh secara signifikan terhadap kepuasan kerja adalah kebebasan bekerja , kejelasan peran, promotion dan kondisi lingkungan kerja, sedangkan variable dependen lain yang diukur diantaranya konflik kerja hubungan dengan rekan kerja , hubungan dengan atasan /supervisor dan gaji tidak signifikan mempengaruhi kepuasan kerja.

Dari uji t pada variabel promosi ditemukan bahwa promosi mepunyai pengaruh yang signifikan namun negatif terhadap kepuasan kerja. Setelah diwawancara lebih lanjut diperoleh beberapa alasan kenapa hal ini bisa terjadi, diantaranya kenaikan atau promosi yang diterima disini kebanyakan tidak ditunjang dengan remunerasi yang seimbang dengan peningkatan tugas dan kewajiban. Selain itu karena kebanyakan mereka adalah perempuan, dimana mereka tidak terlalu berniat untuk mengejar karier melainkan untuk mengisi waktu disela sela kesibukan mengurus rumah tangga. 
Hal ini juga berkaitan dengan hasil bahwa salary tidak mempunyai pengaruh yang signifikan dengan kepuasan kerja. Hal ini mungkin akan berbeda jika responden nya lebih banyak laki-laki .

Tabel 4.10

Hasil Uji t

\begin{tabular}{llll}
\hline VARIABEL & $\mathbf{T}$ & $\mathbf{s i g}$ & KESIMPULAN \\
\hline (Constant) & 4.221 & 0.000 & \\
JOBOTONOMY & 4.170 & 0.000 & Siginifikan positif \\
JOBCLARITY & 5.565 & 0.000 & Siginifikan positif \\
JOBCONFLICT & 0.431 & 0.667 & tidak signifikan \\
COWORKERS & 2.475 & 0.140 & tidak signifikan \\
SUPERVISOR & 0.032 & 0.740 & tidak signifikan \\
SALARY & -0.276 & 0.783 & tidak signifikan \\
PROMOTION & -2.166 & 0.031 & Siginifikan negative \\
WORKCONDITION & 4.001 & 0.000 & Siginifikan positif \\
\hline
\end{tabular}

Variabel Independent Job Satisfaction

Sumber: Data primer diolah (2014).

\subsubsection{Hasil Uji $R^{2}$}

Uji $\mathrm{R}^{2}$ pada Tabel 4.11 diperoleh nilai $\mathrm{R}^{2}$ sebesar 0,513 yang berarti sebesar $51.3 \%$ dari variabel Job satisfaction yang dapat dijelaskan oleh variabel Job Opportunity, Job Clarity, Job Conflict, Co- Worker, Supervision, Salary, Promotion dan work Condition sisanya 48,7 \% dijelaskan oleh model lain maupun sebab-sebab lain diluar model. Nilai Standart Error of Estimate (SEE) sebesar 1.09314 yang artinya nilai SEE masih rendah, sehingga model regresi memiliki ketepatan yang baik dalam memprediksi variabel dependen.

Tabel 4.11

Hasil Uji $\mathrm{R}^{2}$

\begin{tabular}{ccc}
\hline $\mathbf{R}$ & R Square & Std. Error of the Estimate \\
\hline 0,716 & 0,513 & 1.09314 \\
\hline
\end{tabular}

Sumber: Data primer diolah (2014).

\section{Kesimpulan}

Tujuan dari penelitian ini adalah mencari jawaban atas rumusan masalah yang diajukan dalam penelitian yaitu faktor-faktor yang mempengaruhi kepuasan bekerja tenaga pendidik dan kependidikan pada universitas yang ada di Batam. Hasil dari penelitian ini menyimpulkan bahwa kepuasan bekerja dipengaruhi oleh empat faktor utama yaitu otonomi bekerja, kejelasan peran, promosi dan kondisi lingkungan kerja. Sedangkan faktor konflik kerja, rekan kerja, atasan dan 
gaji yang dianggap sangat berpengaruh terhadap kepuasan kerja pada penelitian ini justru tidak mempunyai pengaruh yang signifikan.

Otonomi bekerja menjadi faktor yang sangat mempengaruhi kepuasan kerja, karena dengan responden $85,9 \%$ adalah berpendidikan sarjana, pasca sarjana dan doctoral lebih mengutamakan kepuasan kerja dalam melakukan tugas dan tanggung jawab serta pencapaian tujuan, sehingga apa yang diperoleh lebih memberikan kepuasan kepada kepada tenaga pendidik dan kependidikan dalam bekerja. Begitu juga dengan kejelasan peran, merupakan variabel kedua yang mempengaruhi kepuasan kerja, dimana semakin jelas orang mengetahui tentang apa yang diharapkan dari hasil kerjanya maka semakin orang tersebut merasa puas dengan pekerjaannya.

Kondisi lingkungan kerja mempunyai pengaruh yang signifikan posisif terhadap kepuasan kerja. Dengan lingkungan kerja yang kondusif dan mendukung orang akan lebih dengan senang hati dan puas melakukan pekerjaannya.

Konflik dalam pekerjaan tidak berpengaruh secara siginifikan terhadap kepuasan kerja. Setelah dilakukan wawancara lebih lanjut, hal ini bisa disebabkan karena dalam penelitian ini potensi munculnya konflik kerja hanya $21 \%$ dari jumlah responden yaitu tenaga pendidik yang juga menjabat sebagai pejabat struktural. Untuk tenaga pendidik akan jarang muncul konflik kerja karena mereka cenderung melakukan pekerjaannya sendiri sendiri. Begitu juga dengan tenaga kependidikan, dimana biasanya per fakultas hanya ada 2 sampai 3 orang yang masing masing sudah dengan tugasnya, dan pada level ini konflik kerja jarang muncul.

Hubungan dengan rekan kerja tidak berpengaruh signifikan terhadap kepuasan kerja. Hubungan dengan rekan kerja biasanya berpengaruh positif terhadap kepuasan kerja sebagian besar dilakukan pada level pekerja, staff dan operator ,sementara pada penelitian ini responden dalam kapasitas staff hanya $21 \%$ dari keseluruhan responden. Tenaga pendidik kecendrungan mereka melakukan pekerjaannya tidak terlalu berkaitan satu sama lain, sehingga dalam kasus ini rekan kerja tidak berpengaruh secara signifikan terhadap kepuasan kerja.

Hubungan dengan supervisor tidak berpengaruh secara siginifikan terhadap kepuasan kerja. Hal ini disebabkan karena $85,6 \%$ dari responden sudah berpendidikan tinggi (S1 sampai dengan S3), dimana dengan taraf pendidikan selevel sarjana orang akan lebih confident dan memperhatikan kemampuannya yang pada akhirnya membentuk bargain yang baik, sehingga atasan tidak berpengaruh secara signifikan dengan kepuasan kerja.

Gaji tidak berpengaruh secara siginifikan terhadap kepuasan kerja. Dalam penelitian ini gaji tidak mempunyai pengaruh signifikan terhadap kepuasan kerja, karena responden yang diteliti $65.8 \%$ adalah perempuan, dimana mereka bekerja cenderung hanya untuk mengisi waktu dan mengaktualisasikan diri. 


\section{DAFTAR PUSTAKA}

Akfopure, R.R., Ikhifa, O.G., Imide, O.I., \& Okokoyo, I. E. (2006). Job satisfaction among educators in colleges of education in Southern Nigeria. Journal of Applied Sciences, 6(5), 1094-1098.

Ahmed .I. , Nawaz . M.M , Iqbal . N, Ali.I.,Shaukat. Z, Usman. A.,(2010) Effects of Motivational Factors on Employees Job Satisfaction. a Case Study of University of the Punjab, Pakistan

Abdulla.J, Djebarni. R, Mellahi.K, (2010) Determinants of job satisfaction in the UAE A case study of the Dubai police.

Al- Hussami M (2008) A Study of nurses Job Satisfaction The relationship to organizational Support, transactional Leadership, Transformational Leadership and level of education Eur J.SG 286- 295

Bakotić. D, Babic.T, (2013) Relationship between Working Conditions and Job Satisfaction: The Case of Croatian Shipbuilding Company. International Journal of Business and Social Science Vol. 4 No. 2; February 2013

Bedein, A.G. and A.A Armenakins. 1981. A path Analytic Study of the Consequences of Role Conflict and Ambiguity. Academy of Management Journal, Vol.24, No.2, pp.417-424.

Bigliardi, B., Petroni, A., \& Dormio, A. I. (2005). Organizational socialization, career aspirations and turnover intentions among design engineers. Leadership \& Organization Development Journal, 26(6), 424-441.

Brunetto,Y,V,.Farr,W,R.(2002) Using social identity theory to explain the job satisfaction of public sector employees Brunetto, Yvonne;Farr-Wharton, Rod

The International Journal of Public Sector Management; 2002; 15, 6/7; ProQuest Central pg. 534

Chen, Z (2001). Further investigation of the outcomes of loyalty to supervisor: Job satisfaction and intention to stay Journal of Managerial Psychology; 2001; 16, 7/8; ABI/INFORM Research pg. 650

Chen, L. H. (2008). Job satisfaction among information system (IS) personnel.Computers in Human Behavior, 24, 105-118.

Ellickson MC (2002) Determinant of job satisfaction of municipal government employees ,Public personal, management, fall 200231.3

Fisher, C.D., R.Williams 1983. A Meta Analysis of the Correlates of Role Conflict and role ambiguity. Journal of Applied Psychology

Gaertner, K. N., \& Nollen, S. D. (1992). Turnover Intentions and Desire Among Executives. Human Relations, 45 (5), 447-466.

Gergersen, H. B. and Black, J. S. 1996. Multiple commitment upon repatriation: the Japanese experience. Journal of Management, Vol.22, no.2: 209-229.

Griffin, Ricky W 1986, Relationships among individual, task design, and leader bahaviour variable , Academy of Management Journal (pre - 1986);Des 1980 ;23,4; ABI/INFORM Research pg 665

Hackman, J. R. and Oldham, G. R. 1975. Development of the Job Diagnostic Survey. Journal of Applied Psychology, Vol.60: 159-170.

Hangedorn,L.S (1994) Retirement Pronmity"s role in the prediction of satisfaction in academe. Research in higher education, 35 (6) 711-728 
Heatfield, S.M. (2000). What people want from work: Employee Motivation and Positive Morale.

From

http://humanresources.about.eom/od/rewardrecognition/a/needs_work_2.htm

Hubbert, P.L (2003). Teacher teams: Exploring job satisfaction and work - related factors of teacher collaboration at the middle and high school levels. Dissertation Abstract International , 125

Hunjra Ahmed Imran et al., (2010) Factors A_ecting job satisfaction of employees in Pakistani banking sector, Munich Personal RePEc ArchivePaper No. 32130, posted 28.

Iqbal .A (2013) Impact of Job Autonomy and Supervisor's and Co-Workers' Support on Job Burnout and Satisfaction: The mediating Role of Emotional Labor , International Journal Of Economics Management Sciences Vol2 , No 6 ,2013 pp 67-73

Ibrahim (2012) A Study on Relationship between perception of Suppervisor Support , Organizational Support and Job Satisfaction ; Perceptions of Part-Time MBA , International Journal Of Art and Scient, CD-ROM. ISSN: 1944-6934 :: 5(1):73-83

Jablin, F. M. (1979). Superior-subordinate communication: The state of the art.Psychological Bulletin, 86, 1201-1222.

Kaba, A.(2012) occupational stress and job satisfaction ;A Case study of expatriate lecturers of IIUM; International Journal of Arts \& Sciences, CD-ROM. ISSN: 1944-6934 :: 5(5):273$303(2012)$

Karim, N,A,H.(2010) The Impac Of Work Related Variables on Libraryan's Organizational Commitment and Job Satisfaction, Malaysian Journal of Library \& Information Science, Vol.15, no.3, Dec 2010: 149-163

Khan .R (2012) the meaning of the work ; interpretation proposals for measurement in A Campbell\& PE Conclerse (EDS)

Kim, W.G., Leong, J.K. and Lee, Y. (2005), "Effect Of Service Orientation On Job Satisfaction, Organizational Commitment, And Intention Of Leaving In A Casual Dining Chain Restaurant", Hospitality Management, 24, 171-93.

Kim, B. S. 2001. Commitment of Malaysian workers in Korean multinational enterprises. Malaysian Management Review, Vol.36, no.1: 63-75.

Locke, E. (1976). The nature and causes of job satisfaction. In M.D. Dunnette (Ed.), Handbook of Industrial and Organizational Psychology, 1297-1349. Chicago:RandMcNally

Landy, F.J (1985) Psycology of work behavior .Homewood,IL ;Dorsey Press

Lankau ,M.L (1996) .An examination of mentoring, peer developmental relationships, and team participation as sources of learning in an organization. Dissertation Abstract International , 177

Luthans, F. (1998). Organisational Behaviour. 8th ed. Boston: Irwin McGraw-Hill.

Meyer, J. P. \& Allen, N. J. 1997. Commitment in the Workplace: Theory, Research and Application. Thousand Oaks, California: Sage

Mehmood, Nasir et al., (2012) A Studyof Factors Affecting Job Satisfaction (Evidence from Pakistan).Interdiciplinary Journalof Contemporary Research in Institute of Interdisciplinary Business Research Vol 4, No. 6

Nauman, E. 1993. Antecedents and consequences of satisfaction and commitment among expatriate managers. Group and Organizational Management, Vol.18, no.2: 153-187. 
Nylenna, M., Gulbrandsen, P., Forde, R., \& Aasland, O. G. (2005). Job satisfaction mong Norwegian general practitioners. Scandinavian Journal of Primary Health Care, 23, 198202.

Ooi,K.B., Bakar,N.A.,Arumugam,V ;Does TGM influence employees'job satisfaction ?An Empirical case analysis . International Journal Of Quality and realbility Management Vol 24 No 1 pp 62-77

Pmcus, J. D. (1986). Communication satisfaction, job satisfaction, and job performance. Human Communication Research, 12, 395-419.

Rizzo, J. R., House, J. and Lirtzman, S. I. 1970. Role conflict and role ambiguity in complex organizations. Administrative Science Quarterly, Vol.13: 155-163

Rockman, I. F. (1984). Job satisfaction among faculty and librarians : A study of gender,autonomy and decision making opportunities. Journal of Library Administration, Vol.50, no.3: 43-56

Schulze .S (2006) Factors influencing the job satisfaction of academics in higher education. Unisa Press ISSN $1011 \pm 3487$

Sims, H. P., Szilagyi, A. D., and Mckemey, D. R. 1976. Antecedents of work related expectancies. Academy of Management Journal, Vol.19: 547-559.

Spector, P. E. 1997. Job Satisfaction: Application, Assessment, Causes and Consequences. Thousand Oaks, California: Sage

Spector, P. E. 2000. Industrial and Organizational Psychology: Research and Practice. $2^{\text {nd }}$ ed. New York: John Wiley and Sons.

Scott, D.,Bishop,J.W., \& Chen ,X (2003) . An examination of the relationship of employee involvement with job satisfaction, employee cooperation, and intention to quit in U.S invested enterprise in China . International Journal of Organizational Analysis , 11 (1),3-19

Schuler ,R.S (1979) . A Role perception transactional process model for organizational communication - outcome relathionships . Organizational behavior and Human Performance, 23 ,268-291

Shih, J.S (2000). The effects of job level and supervisor gender on female employees' experiences of supervisor support, supervisor-employee communication, role stress, psychological strain, and job satisfaction. Dissertation Abstract International ,249

Spector, P. E. (1997). Job satisfaction: Application, assessment, causes and consequences. Thousand Oaks, CA: Sage.

Ting . Y (1997) Determinants of job satisfaction of federal government employees Public Personnel Management; Fall 1997; 26, 3; ABI/INFORM Research pg. 313

Volkwein, J. F., \& Zhou, Y. (2003). Testing a model of administrative job satisfaction. Research in Higher Education, 44 (2), 149-171.

Watson, A. J., Hatton, N. G., Squires, D. S., \& Soliman, I. K. (1991). School staffing and the quality of education: Teacher adjustment and satisfaction. Teaching and Teacher Education, 7(1), 63-77.

Wong . E.S.K , Heng .T.N (2009) Case Study of Factors Influencing Jobs Satisfaction in Two Malaysian Universities; International Business research Vol 2. No 2

Wheeless,V.E,. Wheeless ,L.R., \& Howard R.D (1983) An Analysis of the contribution of participative decision making and communication with supervisor as predictors of job satisfaction. Research in higher education ,18(2) 145-160 
Wadhwa.D.S, Verghese M., 3Wadhwa. DS A Study on Factors Influencing Employee Job satisfaction -A Study in Cement Industry of Chhattisgarh

Yousef, Darwis A..2002. Job Satisfaction as a Mediator of The Relationship between Role Stressors and Organizational Commitment: A Study fron An Arabic Cultural Perspective. Journal of Management Psychology, Vol.17, No.4, pp.250-266. 